\title{
Does the classification of cerebral palsy influence caries experience in children and adolescents?
}

\author{
Michele Baffi Diniz ${ }^{1}$, Renata Oliveira Guaré1, Maria Cristina Duarte Ferreira², \\ Maria Teresa Botti Rodrigues Santos ${ }^{3}$ \\ ${ }^{1}$ Universidade Cruzeiro do Sul - UNICSUL, School of Dentistry, Department of Pediatric Dentistry, São Paulo, SP, Brazil \\ ${ }^{2}$ Centro Universitário SENAC, Department of Dentistry, São Paulo, SP, Brazil \\ ${ }^{3}$ Universidade Cruzeiro do Sul - UNICSUL, School of Dentistry, Department of Patients with Special Needs, São Paulo, SP, Brazil
}

\begin{abstract}
Aim: To evaluate the influence of the classification of cerebral palsy (CP) on the caries experience in children and adolescents, and determine the types of teeth most affected by dental caries. Methods: A total of 181 individuals with $C P$, aged $8.30 \pm 4.10$ years were examined for dental caries diagnosis in primary, mixed and permanent dentitions. The sample consisted of 96 quadriplegic individuals, 56 diplegic, 18 hemiplegic and 11 with choreoathetosis. The groups were compared using Kruskal-Wallis and Chi-square tests. Univariate logistic regression models were used to identify whether age was a predictor of caries risk $(\alpha=5 \%)$. Results: The sample was homogeneous as regards sex and age, among patients with quadriplegia, diplegia, hemiplegia and choreoathetosis. Out of the total sample, $51.4 \%$ of the individuals were caries free. The overall mean for the dmft and DMFT indices were $1.70 \pm 3.30$ and $0.70 \pm 1.60$, respectively. The mean caries experience in primary, mixed and permanent dentitions did not vary significantly according to the $\mathrm{CP}$ classification ( $\mathrm{p}>0.05)$. Child's age was a predictor for dental caries experience $(p<0.05)$. Conclusions: The CP classification did not influence on caries experience, and the teeth most affected by dental caries were the primary and first permanent molars.
\end{abstract}

Keywords: dental caries; cerebral palsy; oral hygiene; preventive dentistry.

\section{Introduction}

Cerebral palsy $(\mathrm{CP})$ describes a group of permanent disorders involving movement and posture development that cause activity limitations. These are attributed to nonprogressive disturbances occurring in the developing fetal or

Received for publication: January 21, 2015 Accepted: March 17, 2015

Correspondence to: Michele Baffi Diniz Universidade Cruzeiro do Sul Setor de Pós Graduação Rua Galvão Bueno, 868 - Liberdade CEP: 01506-000 - São Paulo-SP - Brazil Phone: +55 1133853015 - Fax: +55 1133853015

E-mail: mibdiniz@hotmail.com infant brain. CP motor disorders are often accompanied by epilepsy, secondary musculoskeletal problems and disturbances of sensation, perception, cognition, communication and behavior. This condition is the most common cause of severe physical disability in childhood ${ }^{1-2}$.

The type of abnormal resting muscle tone or involuntary movement disorder observed or elicited is usually assumed to be related to the underlying pathophysiology of the condition. Individuals with spastic cerebral palsy present increased tone, pathological reflexes and hyperreflexia or pyramidal signs, with clinical patterns of involvement including: quadriplegia, more severe motor involvement of all four limbs; diplegia, involvement of corresponding limbs, 
although typically more severe in the legs; and hemiplegia, affecting one side. Individuals with dyskinesia (choreoathetosis) present involuntary, uncontrolled, recurring and occasionally stereotyped movements, which may be totally disabling when severe ${ }^{3}$.

Dental caries is an oral health burden in individuals with $\mathrm{CP}$, not only in primary but also in permanent dentition, with higher percentages of decayed and missing teeth ${ }^{4-5}$. Children with CP can present a reduced unstimulated salivary flow rate, $\mathrm{pH}$ and buffer capacity, which may compromise the protective function of saliva, resulting in increased risk of oral diseases ${ }^{6}$.

Maintaining the oral health of individuals with $\mathrm{CP}$ requires systematic hygiene practices that demand supervision, or their oral hygiene may eventually have to be performed by family caregivers. A child's development needs the family's participation, involvement and support. When this is well-structured, it will positively contribute to the child's quality of life. However, in individuals with CP, this process of participation, involvement and support is not restricted to the developmental period. The task of taking care of a child with complex disabilities at home may be somewhat daunting for caregivers, and may reflect the way in which these individuals are cared for ${ }^{5,7}$

The purposes of this study were to assess the influence of the classification of $\mathrm{CP}$ on caries experience in children and adolescents, and determine the type of teeth most affected by dental caries. The null hypothesis is that the classification of CP does not influence on caries experience in children and adolescents.

\section{Material and methods}

This cross-sectional study was approved by the Human Research Ethics Committee of the Cruzeiro do Sul University, Protocol No. 152/2011, and was conducted in accordance with the ethical standards stated in the Declaration of Helsinki.

To calculate the sample size, the used formula considered a confidence interval of $95 \%$, statistical power of $80 \%$, mean caries prevalence of 5.43, standard deviation of 4.17 and a mean minimum difference of 4.56 to be detected ${ }^{8}$. Thus, a minimum of 181 individuals was required.

The sample consisted of non-institutionalized children and adolescents (110 male and 71 female) presenting a medical diagnosis of $\mathrm{CP}$, age-range from 1 to 17 years (mean age, 8.30 \pm 4.10 ), and participating in a prevention-based program for oral health. The study was conducted in the State of São Paulo, Brazil, in a rehabilitation centre between April and December 2011. Written informed consent for participation and publication was obtained from the parents or guardians of each individual with $\mathrm{CP}$, who agreed to participate in the study.

Patient medical records were reviewed for clinical data, including gender, age and CP classification (choreoathetosis, quadriplegia, diplegia or hemiplegia).

A single calibrated examiner (weighted Kappa $=0.89$ ) conducted the oral examination with the help of an assistant to record the data. Before clinical examination, professional tooth cleaning was performed in each patient. The patients' teeth were assessed under a reflector light using a dental mirror and a probe after drying with a 3-in-1 syringe. The World Health Organization criteria ${ }^{9}$ were used for recording dental caries experience by the decayed, missing and filled teeth index, using the dmft and DMFT indices for primary and permanent dentition, respectively. In children with mixed dentition, dmft and DMFT were recorded together. No radiographic examination was performed.

\section{Statistical Analysis}

Descriptive statistical tests were used to assess the demographic data using SPSS software program (Statistics Package for Social Science, version 15.0 for Windows). The measures of central tendency (mean) and dispersion (standard deviation) were used for continuous variables. Participants were divided into groups according to their clinical type of CP: choreoathetosis $(n=11)$; quadriplegia $(n=96)$; diplegia $(n=56)$; and hemiplegia $(n=18)$. The nonparametric Chisquare and Kruskal-Wallis tests were used to determine significant differences in data.

The teeth most affected by dental caries in primary and permanent dentitions were assessed for subsequent regression analysis. Univariate logistic regression models were used to identify whether CP child's age was a predictor of caries risk in each tooth assessed, using the tooth status (presence or absence of caries) as the dependent variable and age as an independent variable. A logistic regression model was also performed considering sex, age in years and CP classification as potential independent variables that could influence on dental caries experience (outcome). The significance level was set at $5 \%$.

\section{Results}

Table 1 shows the distribution of the 181 participants according to dentition, sex, age (years) and CP classification. The sample was homogeneous as regards dentition $(p=0.6454)$, sex $(p=0.6829)$ and age $(0.1932)$ among the quadriplegia, diplegia, hemiplegia and choreoathetosis groups. The sample consisted of a higher percentage of males $(60.8 \%)$ than females. According to the $\mathrm{CP}$ classification, most of the individuals with CP presented quadriplegia $(53.1 \%)$, followed by diplegia $(30.9 \%)$, hemiplegia $(9.9 \%)$ and choreoathetosis $(6.1 \%)$.

The overall mean for the $\mathrm{dmft}$ and DMFT indices were $1.70 \pm 3.30$ and $0.70 \pm 1.60$, respectively. Table 2 shows the distribution of caries experience in primary, mixed and permanent dentition according to the $\mathrm{CP}$ classification. In the total sample, 93 participants $(51.4 \%)$ presented no decay. At least one primary or permanent tooth affected by caries was identified in 88 patients $(48.6 \%)$. The diplegia group presented more caries experience $(60.7 \%)$ than the others. The mean caries experience in primary, mixed and permanent dentitions did not vary significantly according to the $\mathrm{CP}$ classification $(p>0.05)$. 
Table 1. Distribution (\%) of the 181 participants according to dentition, sex, age and the classification of $\mathrm{CP}$

\begin{tabular}{|c|c|c|c|c|c|}
\hline \multirow[t]{2}{*}{ Dentition } & \multicolumn{5}{|c|}{ Classification of $\mathrm{CP}$} \\
\hline & $\begin{array}{l}\text { Quadriplegia } \\
\qquad(n=96)\end{array}$ & $\begin{array}{l}\text { Diplegia } \\
(n=56)\end{array}$ & $\begin{array}{l}\text { Hemiplegia } \\
\quad(n=18)\end{array}$ & $\begin{array}{l}\text { Choreoathetosis } \\
\qquad(n=11)\end{array}$ & $p$ value \\
\hline Deciduous & $33(34.4)$ & $12(21.4)$ & $7(38.9)$ & $4(36.4)$ & $0.6454^{*}$ \\
\hline Mixed & $39(40.6)$ & $29(51.8)$ & $8(44.4)$ & $4(36.4)$ & \\
\hline Permanent & $24(25.0)$ & $15(26.8)$ & $3(16.7)$ & $3(27.2)$ & \\
\hline \multicolumn{6}{|l|}{ Sex } \\
\hline Male & $59(61.5)$ & 32 (57.1) & $13(72.2)$ & $6(54.5)$ & $0.6829 *$ \\
\hline Female & $37(38.5)$ & $24(42.9)$ & $5(27.8)$ & $5(45.5)$ & \\
\hline \multicolumn{6}{|l|}{ Age (years) } \\
\hline $\begin{array}{l}\text { Average } \pm \\
\text { standard deviation }\end{array}$ & $8.0 \pm 4.3$ & $9.3 \pm 4.0$ & $7.2 \pm 3.9$ & $8.5 \pm 3.8$ & $0.1932^{* *}$ \\
\hline
\end{tabular}

Table 2. Distribution of caries experience (mean \pm standard deviation) in primary, mixed and permanent dentitions according to the classification of $\mathrm{CP}$

\begin{tabular}{lccccc}
\hline $\begin{array}{l}\text { Classification of CP } \\
\text { (n) }\end{array}$ & $\begin{array}{c}\text { Caries } \\
\text { experience }=0 \\
n(\%)\end{array}$ & $\begin{array}{c}\text { Caries } \\
\text { experiencee } \geq 1 \\
n(\%)\end{array}$ & $\begin{array}{c}\text { Primary } \\
\text { dentition } \\
(\mathbf{n}=56)\end{array}$ & $\begin{array}{c}\text { Mixed } \\
\text { dentition } \\
(\mathbf{n}=80)\end{array}$ & $\begin{array}{c}\text { Permanent } \\
\text { dentition } \\
(\mathbf{n}=45)\end{array}$ \\
Quadriplegia (96) & $53(55.2)$ & $43(44.8)$ & $1.5 \pm 3.5^{\mathrm{a}}$ & $3.4 \pm 4.3^{\mathrm{a}}$ & $1.3 \pm 1.8^{\mathrm{a}}$ \\
Diplegia (56) & $22(39.3)$ & $34(60.7)$ & $1.1 \pm 2.5^{\mathrm{a}}$ & $3.4 \pm 3.1^{\mathrm{a}}$ & $2.7 \pm 2.8^{\mathrm{a}}$ \\
Hemiplegia (18) & $11(61.1)$ & $7(38.9)$ & $2.6 \pm 5.1^{\mathrm{a}}$ & $0.9 \pm 1.1^{\mathrm{a}}$ & $0.0 \pm 0.0^{\mathrm{a}}$ \\
Choreoathetosis (11) & $7(63.6)$ & $4(36.4)$ & $7.3 \pm 8.4^{\mathrm{a}}$ & $1.5 \pm 3.0^{\mathrm{a}}$ & $2.0 \pm 3.5^{\mathrm{a}}$ \\
\hline $\mathrm{p}$ value & - & - & 0.3609 & 0.1698 & 0.0664 \\
\hline
\end{tabular}

*Within columns, significant differences are represented by different superscript lowercase letters (Kruskall-Wallis test; $p<0.05$ ).

The mean and standard deviation age of the individuals with $\mathrm{CP}$ was $3.6 \pm 1.6$ years for primary dentition, $8.7 \pm 2.1$ years for mixed dentition and $13.4 \pm 2.0$ years for permanent dentition. In primary, mixed and permanent dentitions, $73.2 \%, 37.5 \%$ and $48.9 \%$ individuals, respectively, were caries free. Although the sample had $60.8 \%$ male individuals, there was no statistical difference as regards sex when dental caries was absent $(\mathrm{p}=0.1384)$ or present $(p=0.8884)$ according to the primary, mixed and permanent dentitions.

Figure 1 shows the prevalence of caries in primary and permanent dentitions in individuals with CP. In both maxillary and mandibular arches, primary molars and first permanent molars were the teeth most affected by caries disease. Maxillary anterior teeth were more affected by caries than mandibular anterior teeth, particularly in primary dentition. The permanent teeth most affected by dental caries were the mandibular first molars, followed by the maxillary first molars. The primary teeth most affected were second molars, followed by first molars. The univariate logistic regression, considering CP child's age as a predictor for caries in primary and first permanent molars, confirmed that CP child's age was not a predictor for caries in primary molars $(p>0.05)$. Considering the first permanent molars, $\mathrm{CP}$ child's age was a predictor for caries in tooth \#16 and tooth \#36 $(\mathrm{p}<0.05)$ when they were analyzed separately. However, when the maxillary and mandibular first permanent molars were analyzed together, the results

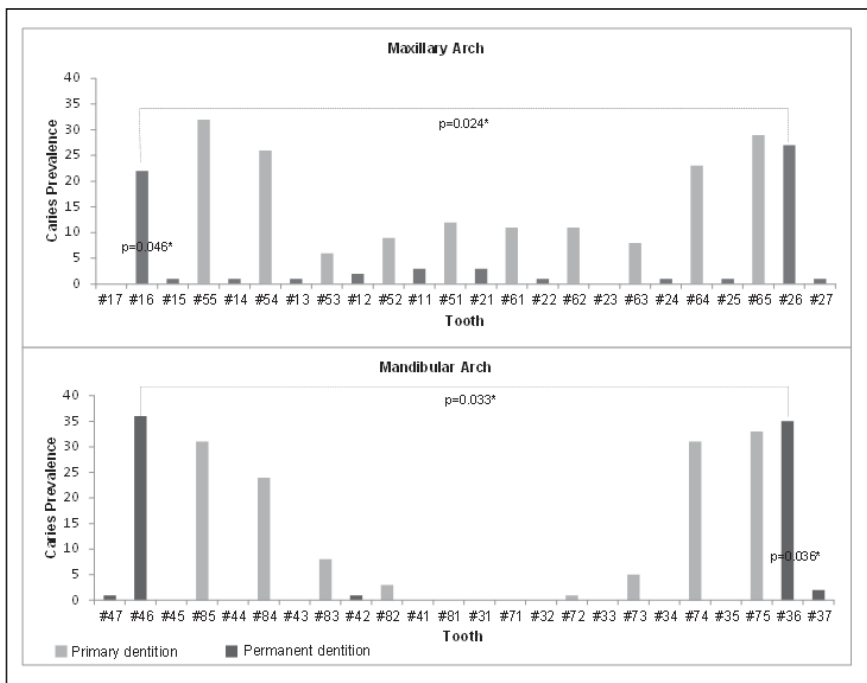

Fig. 1. Prevalence of caries in primary and permanent dentitions in participants with CP. *Significant association between age and presence of caries by logistic regression $(p<0.05)$

confirmed that CP child's age was a predictor for dental caries $(\mathrm{p}<0.05)$.

Table 3 shows the logistic regression model considering sex, age and $\mathrm{CP}$ classification as predictors on dental caries experience. It could be seen that age (years) had a significant effect on dental caries experience $(p<0.05)$ in children with CP. Sex and CP classification had no significant influence $(\mathrm{p}>0.05)$. 
Table 3. Logistic regression analysis considering child's age, sex and CP classification as predictors for the presence of caries

\begin{tabular}{llllll}
\hline Variable & p value & Odds Ratio & \multicolumn{2}{c}{ 95\% Confidence Interval } \\
& & & 0.1578 & 2.1563 \\
CP classification & Choreoathetosis & 0.4190 & 0.5833 & 0.7710 & 3.0003 \\
& Diplegia & 0.2263 & 1.5210 & 0.91992 & 1.7002 \\
Hemiplegia & 0.3223 & 0.5820 & 1.0056 & 1.1627 \\
Age (years) & $0.0347^{*}$ & 1.0813 & 0.6472 & 2.2180 \\
\hline
\end{tabular}

${ }^{*}$ Significant association between by logistic regression $(p<0.05)$.

\section{Discussion}

Clinically, CP varies in severity and highly diverse levels of functional independence can be observed in individuals with the same medical diagnosis, due to the extent of neurodevelopmental disorder ${ }^{1,3}$. Spastic CP (quadriplegia, diplegia and hemiplegia) is by far the most common type of movement disorders in cerebral palsy, occurring in $70 \%$ to $80 \%$ of all cases ${ }^{1}$, as observed in this study. This study was conducted in a reference rehabilitation centre for individuals with CP presenting more complex disorders, as observed in the composition of the sample. Most of those subjects presented a quadriplegic and diplegic CP classification, as previously described by Dos Santos and Nogueira9 ${ }^{9}$ (2005). Moreover, $60.8 \%$ of children and adolescents with $\mathrm{CP}$ were male, which agrees with the results found by Bax et al. ${ }^{10}$ (2006).

It was hypothesized that the increased orofacial muscular tonus and involuntary movements in individuals with CP could have an influence on caries experience, since these characteristics are considered factors leading to difficulty with performing effective oral hygiene ${ }^{11}$. However, it was observed that the CP classification had no influence on caries experience in these individuals. This could be explained by the implementation of an educational program on oral health directed to the caregivers, who acquired knowledge concerning the main diseases that affected the oral cavity of children with $\mathrm{CP}$ and forms of prevention and maintenance of oral health. Moreover, age was a predictor for dental caries experience. In other words, caries experience increases as the individual's age increases. It could be observed that $\mathrm{CP}$ children with diplegia presented a tendency of higher DMFT index in permanent dentition, since these individuals were older than the others and presented more erupted teeth in the oral cavity.

In a previous study ${ }^{9}$, comparisons between CP classifications determined higher values for $\mathrm{dmft}$ and DMFT indices among spastic quadriplegic patients. However, the control of caries risk factors is gradually becoming more effective, in a process that involves growing caregiver's knowledge concerning oral hygiene habits, the use of open mouth devices to facilitate toothbrushing, use of fluoride dentifrice and diet control. The fact that the patients were treated in a rehabilitation centre providing constant preventive care might also be a factor in the low $\mathrm{dmft}$ and DMFT indices obtained ${ }^{12}$.

With regard to the risk of dental caries, the greatest risk is observed in children from low-income families, most often from minority groups and families that include individuals with special care needs ${ }^{13}$, particularly $\mathrm{CP}^{5,8,10,14}$. According to the American Academy of Pediatric Dentistry, they show a moderate risk of caries ${ }^{15}$. Dental caries in individuals with CP could be also related to intellectual disability ${ }^{4}$, oromotor dysfunction ${ }^{8,16}$, the regular use of sugary anticonvulsant drugs ${ }^{17}$, shorter mastication endurance time ${ }^{18}$, biting reflexes ${ }^{9}$ and worse quality of life and continual burden on the caregivers $^{5,8}$, which can further influence oral hygiene ${ }^{8}$. Despite presenting those risk factors, it may be observed that since the individuals with $\mathrm{CP}$ are under a continuous preventive follow-up dental care, caries experience can be controlled. Moreover, the mean $\mathrm{dmft}$ and DMFT indices of the individuals with $\mathrm{CP}$ were lower than the dental caries indices of normoreactive Brazilian children according to the last national survey of dental health ${ }^{19}$.

In this study, there was no difference between age and $\mathrm{CP}$ classification. It should be stressed that the mean age was expressed in years and not in number of months and might influence the results. For primary dentition, age was similar to that shown in other studies ${ }^{5,8}$. In a clinical study involving patients with CP, Roberto et al. ${ }^{20}$ (2012) observed that as the primary teeth erupted, the dmft index increased. For mixed dentition, considering both the dmft and the DMFT indices, the caries experience was lower in comparison with previous studies ${ }^{5,8}$. This difference could be explained by the participation of the caregivers in a systematic prevention program developed at the Rehabilitation Centre. For permanent dentition, the caries experience was similar in comparison with the study of de Carvalho et al. ${ }^{21}$ (2011), and in disagreement with Santos et al. ${ }^{5}$ (2010), who reported higher DMFT indices. These differences may be attributed to the location where the study was conducted and the severity of CP in these two populations.

In order to determine the risk of developing oral diseases it is fundamental to identify the types of teeth that are most affected by dental caries in individuals with $\mathrm{CP}$, to determine the types of primary and permanent teeth most affected by caries according to CP child's age. To the best of the authors' knowledge, this is the first study to assess the types of primary and permanent teeth most affected by caries according to CP child's age. The difficulty in maintaining the patient's mouth open, due to the muscle tonus ${ }^{1}$, hyper-responsivity to oral hygiene stimulus and oral manipulation ${ }^{1}$, and non- 
cooperative behavior ${ }^{4}$ could contribute to food residues on the occlusal surfaces of posterior teeth, as observed on the permanent first molars and the primary first and second molars. Primary second molars and primary and permanent first molars were the most powerful predictors for assignment to the risk group ${ }^{13}$. Motta et al. ${ }^{22}$ (2012) found that first permanent molars are the teeth most affected by dental caries.

The mandibular anterior teeth were less affected by dental caries than the maxillary anterior teeth, as also occurs in children without any neurological damage. This could be explained by tongue movement and by the fact that a greater salivary film velocity occurs lingual to the mandibular incisors, where biofilm is most readily removed ${ }^{23}$. With regard to $\mathrm{CP}$ child's age as a predictor for caries in first permanent molars, analysis showed that these teeth presented greater caries risk with increasing age.

Based on these findings, it seems reasonable to assume that the prevention program requires greater focus on issues specific to this population, including: detailed advice concerning sealant application; fluoride therapy; use of $0.12 \%$ chlorhexidine digluconate oral rinse; toothbrushes adapted to facilitate handling by individuals with $\mathrm{CP}$, so they can perform their own oral hygiene wherever possible; the use of dental floss devices; single-tuft toothbrushes for use on occlusal surfaces; and facilitating mouth opening with the use of a dental wooden spatula. All patients with $\mathrm{CP}$ should have their dental visits scheduled at shorter time intervals, in order to ensure the best professional care, including constant follow-up of erupting teeth on an individual basis.

In this study, caries experience was assessed by the DMFT and $\mathrm{dmft}$ indices proposed by the $\mathrm{WHO}^{24}(2013)$, because this population presents limited cooperation for a more detailed clinical examination of dental caries using other indexes, and incipient enamel lesions (i.e., white spot lesions) were not evaluated. The examiner was calibrated for the indices and is a dental professional who frequently examines and treats children with CP. The same examiner has previously conducted other studies using these indexes ${ }^{5,8-9,16,25}$. Moreover, there was no control group of patients without alteration. Another research has compared children with $\mathrm{CP}$ with normorreactive subjects $^{26}$, but the mentioned study assessed a small number of patients compared with this investigation.

Another limitation of the present investigation relates to the different number of subjects in each CP classification, which may have influenced the results. Despite the quantitative differences between the assessed groups, they correspond to the percentages found in the population, with a higher prevalence of quadriplegia.

In conclusion, the $\mathrm{CP}$ classification had no influence on caries experience, and the teeth most affected by dental caries were the primary molars and first permanent molars.

\section{References}

1. Rosenbaum P, Paneth N, Leviton A, Goldstein M, Bax M, Damiano D, et al. A report: the definition and classification of cerebral palsy April 2006. Dev Med Child Neurol Suppl. 2007; 109: 8-14.
2. Oskoui M, Coutinho F, Dykeman J, Jetté N, Pringsheim T. An update on the prevalence of cerebral palsy: a systematic review and meta-analysis. Dev Med Child Neurol. 2013; 55: 509-19.

3. Bax MC, Flodmark O, Tydeman C. Definition and classification of cerebral palsy. From syndrome toward disease. Dev Med Child Neurol Suppl. 2007; 109: 39-41.

4. Moreira RN, Alcântara CE, Mota-Veloso I, Marinho SA, Ramos-Jorge ML, Oliveira-Ferreira F. Does intellectual disability affect the development of dental caries in patients with cerebral palsy? Res Dev Disabil. 2012; 33: 1503-7.

5. Santos MT, Biancardi M, Guare RO, Jardim JR. Caries prevalence in patients with cerebral palsy and the burden of caring for them. Spec Care Dentist. 2010; 30: 206-10.

6. Santos MT, Guaré R, Leite M, Ferreira MC, Nicolau J. Does the neuromotor abnormality type affect the salivary parameters in individuals with cerebral palsy? J Oral Pathol Med. 2010; 39: 770-4.

7. Abanto J, Ortega AO, Raggio DP, Bönecker M, Mendes FM, Ciamponi AL. Impact of oral diseases and disorders on oral-health-related quality of life of children with cerebral palsy. Spec Care Dentist. 2014; 34: 56-63.

8. Rodrigues dos Santos MT, Bianccardi M, Celiberti P, de Oliveira Guaré R. Dental caries in cerebral palsied individuals and their caregivers' quality of life. Child Care Health Dev. 2009; 35: 475-81.

9. Dos Santos MT, Nogueira ML. Infantile reflexes and their effects on dental caries and oral hygiene in cerebral palsy individuals. J Oral Rehabil. 2005; 32: 880-5.

10. Bax M, Tydeman C, Flodmark O. Clinical and MRI correlates of cerebral palsy: the European Cerebral Palsy Study. JAMA. 2006; 296: 1602-8.

11. Dourado M da R, Andrade PM, Ramos-Jorge ML, Moreira RN, OliveiraFerreira F. Association between executive/attentional functions and caries in children with cerebral palsy. Res Dev Disabil. 2013; 34: 2493-9.

12. Sehrawat N, Marwaha M, Bansal K, Chopra R. Cerebral palsy: a dental update.Int J Clin Pediatr Dent. 2014; 7: 109-18.

13. Helm S, Helm T. Correlation between caries experience in primary and permanent dentition in birth-cohorts 1950-70. Scand J Dent Res. 1990; 98: 225-7.

14. Cardoso AM, Gomes LN, Silva CR, Soares R de S, de Abreu MH, Padilha WW, et al. Dental caries and periodontal disease in Brazilian children and adolescents with cerebral palsy. Int J Environ Res Public Health. 2014; 12: 335-53.

15. American Academy of Pediatric Dentistry. Reference manual. Guideline on caries-risk assessment and management for infants, children, and adolescents. Pediatr Dent. 2013; 35: 118-25.

16. Santos MTBR, Ferreira MCD, Guaré RO, Nascimento AO, Jardim JR. Ora hydration in children with cerebral palsy. Braz Oral Sci. 2014; 13: 140-5.

17. Siqueira WL, Santos MT, Elangovan S, Simoes A, Nicolau J. The influence of valproic acid on salivary $\mathrm{pH}$ in children with cerebral palsy. Spec Care Dentist. 2007; 27: 64-6.

18. Santos MT, Manzano FS, Chamlian TR, Masiero D, Jardim JR. Effect of spastic cerebral palsy on jaw-closing muscles during clenching. Spec Care Dentist. 2010; 30: 163-7.

19. Ministry of Health of Brazil. Oral health conditions of the Brazilian population 2010. Main Results. Brasilia: Ministry of Health; 2011.

20. Roberto LL, Machado MG, Resende VL, Castilho LS, Abreu MH. Factors associated with dental caries in the primary dentition of children with cerebral palsy. Braz Oral Res. 2012; 26: 471-7.

21. de Carvalho RB, Mendes RF, Prado RR Jr, Moita Neto JM. Oral health and oral motor function in children with cerebral palsy. Spec Care Dentist. 2011; 31: 58-62.

22. Motta LJ, Santos JG, Alfaya TA, Guedes CC, Godoy CHL, Bussadori SK. Clinical status of permanent first molars in children aged seven to ten years in a Brazilian rural community. Braz J Oral Sci. 2012; 11: 475-80.

23. Dawes $\mathrm{C}$. Why does supragingival calculus form preferentially on the lingual surface of the 6 lower anterior teeth? J Can DentAssoc. 2006; 72 923-6. 
24. World Health Organization. Oral Health Surveys: Basic Methods. 5th ed. Geneva: World Health Organization; 2013.

25. Santos MT, Ferreira MC, Mendes FM, de Oliveira Guaré R. Assessing salivary osmolality as a caries risk indicator in cerebral palsy children. Int J Paediatr Dent. 2014; 24: 84-9.

26. Guaré Rde O, Ciamponi AL. Dental caries prevalence in the primary dentition of cerebral-palsied children. J Clin Pediatr Dent. 2003; 27: 287-92. 